\title{
State Medicaid Expansion Tobacco Cessation Coverage and Number of Adult Smokers Enrolled in Expansion Coverage — United States, 2016
}

\author{
Anne DiGiulio ${ }^{1}$; Meredith Haddix ${ }^{1}$; Zach Jump, MA ${ }^{1}$; Stephen Babb, MPH²; Anna Schecter, MPH²; Kisha-Ann S. Williams, MPH²;
} Kat Asman, $\mathrm{MSPH}^{2}$; Brian S. Armour, $\mathrm{PhD}^{2}$

In $2015,27.8 \%$ of adult Medicaid enrollees were current cigarette smokers, compared with $11.1 \%$ of adults with private health insurance, placing Medicaid enrollees at increased risk for smoking-related disease and death (1). In addition, smoking-related diseases are a major contributor to Medicaid costs, accounting for about $15 \%$ ( $>$ \$39 billion) of annual Medicaid spending during 2006-2010 (2). Individual, group, and telephone counseling and seven Food and Drug Administration (FDA)-approved medications are effective treatments for helping tobacco users quit (3). Insurance coverage for tobacco cessation treatments is associated with increased quit attempts, use of cessation treatments, and successful smoking cessation (3); this coverage has the potential to reduce Medicaid costs (4). However, barriers such as requiring copayments and prior authorization for treatment can impede access to cessation treatments $(3,5)$. As of July 1 , 2016, 32 states (including the District of Columbia) have expanded Medicaid eligibility through the Patient Protection and Affordable Care Act (ACA), ${ }^{*} \dagger$ which has increased access to health care services, including cessation treatments (5). CDC used data from the Centers for Medicare and Medicaid Services (CMS) Medicaid Budget and Expenditure System (MBES) and the Behavioral Risk Factor Surveillance System (BRFSS) to estimate the number of adult smokers enrolled in Medicaid expansion coverage. To assess cessation coverage among Medicaid expansion enrollees, the American Lung Association collected data on coverage of, and barriers to accessing, evidence-based cessation treatments. As of December 2015, approximately 2.3 million adult smokers were newly enrolled in Medicaid because of Medicaid expansion. As of July 1, 2016, all 32 states that have expanded Medicaid eligibility under ACA covered some cessation treatments for all Medicaid expansion enrollees, with nine states covering all nine cessation treatments for all Medicaid expansion enrollees. All 32 states imposed

\footnotetext{
${ }^{*}$ http://kff.org/health-reform/slide/current-status-of-the-medicaid-expansiondecision.

$\dagger$ Coverage for the adult expansion population must be offered through an alternative benefit plan. States generally have expanded coverage in one of two ways: by extending traditional Medicaid coverage to the Medicaid expansion population or by creating a benefit package that is not aligned with the state's traditional Medicaid state plan and using managed care for the expansion population. States can also provide subsidies to this population that are used to purchase coverage offered in the state or federally facilitated marketplace created by the Patient Protection and Affordable Care Act.
}

one or more barriers on at least one cessation treatment for at least some enrollees. Providing barrier-free access to cessation treatments and promoting their use can increase use of these treatments and reduce smoking and smoking-related disease, death, and health care costs among Medicaid enrollees (4,6-8).

A Healthy People 2020 objective (TU-8) calls for all state Medicaid programs to adopt comprehensive coverage of smoking cessation treatments. ${ }^{\S} \mathrm{A}$ previous study reported on state Medicaid coverage of cessation treatments during 2014-2015 in the population traditionally eligible for Medicaid coverage (9), but cessation coverage has not been reported among the population newly eligible for Medicaid expansion coverage in the 32 states (including the District of Columbia) that expanded Medicaid eligibility through ACA as of July 1, 2016. These states elected to expand coverage to a new eligibility group of adults aged $<65$ years known as the Medicaid expansion population (also known as the VIII group).

To estimate the number of adult cigarette smokers enrolled in Medicaid expansion coverage, 2014 BRFSS estimates of state-specific smoking prevalence among self-reported Medicaid enrollees were multiplied by $\mathrm{MBES}^{* *}$ enrollment data for December 2015. Newly eligible Medicaid enrollees were defined as persons who were newly enrolled in Medicaid because of ACA Medicaid expansion. Some states expanded Medicaid eligibility to varying extents before ACA was enacted. The overall Medicaid expansion population estimates (Table 1) include persons who enrolled in Medicaid because of these previous state expansion actions, as well as persons who enrolled in Medicaid because of state Medicaid expansions under ACA. The newly eligible Medicaid population estimates include the latter group only.

\footnotetext{
$\$$ https:/www.healthypeople.gov/2020/topics-objectives/topic/tobacco-use/ objectives.

S Data were obtained from the Behavioral Risk Factor Surveillance System (BRFSS) 2014 health care access module (http://www.cdc.gov/brfss/). Smoking prevalence estimates were calculated for 2014 BRFSS respondents aged 18-64 years who reported the following: 1) smoking $\geq 100$ cigarettes during their lifetimes and smoking every day or some days at the time of the interview, and 2) having Medicaid or another state program as the primary source of their health care coverage. The relevant BRFSS question did not distinguish between traditional and expansion Medicaid coverage.

** https://www.medicaid.gov/medicaid-chip-program-information/programinformation/medicaid-and-chip-enrollment-data/medicaid-enrollment-datacollected-through-mbes.html and http://kff.org/medicaid/issue-brief/ an-overview-of-new-cms-data-on-the-number-of-adults-enrolled-in-the-acamedicaid-expansion/.
} 
To assess cessation coverage available to the state Medicaid expansion population as of July 1, 2016, the American Lung Association collected data on coverage of, and barriers to accessing, all evidence-based cessation treatments except telephone counseling $^{\dagger \dagger}$ (a total of nine treatments) for state Medicaid expansion populations. The American Lung Association compiled data from Medicaid member websites and handbooks; Medicaid provider websites and handbooks; policy manuals; plan formularies and preferred drug lists; Medicaid state plan amendments; and relevant regulations and legislation. Personnel from state Medicaid agencies and health departments or other state government agencies were consulted to confirm the accuracy of collected information, retrieve missing documents, and reconcile discrepancies. Data were collected during July 19-August 18, 2016.

As of December 2015, approximately 3.3 million adult cigarette smokers were enrolled in Medicaid expansion coverage, including approximately 2.3 million adults who were newly eligible for Medicaid expansion coverage (Table 1). The number of adult smokers enrolled in Medicaid expansion coverage ranged from 2,567 in Alaska to 618,395 in New York; the number of newly eligible adult smokers enrolled in this coverage ranged from 2,567 in Alaska to 291,351 in Pennsylvania (Table 1).

As of July 1, 2016, nine of the 32 states that have expanded Medicaid eligibility (Colorado, Connecticut, Indiana, Massachusetts, Minnesota, North Dakota, Ohio, Pennsylvania, and Vermont) covered all nine cessation treatments for all Medicaid expansion enrollees (Table 2). Of the 32 states, 17 states covered individual counseling for all Medicaid expansion enrollees, 11 covered group counseling for all enrollees, and 19 covered all seven FDA-approved cessation medications for all enrollees. All 32 states imposed at least one barrier (e.g., copayments or prior authorization) on at least one treatment for at least some enrollees (Table 3). Six states required copayments for at least one cessation treatment for all enrollees, with an additional seven states requiring copayments for some enrollees. Twelve states required prior authorization to obtain at least one cessation treatment for all enrollees, with an additional 14 states requiring prior authorization for some enrollees.

\footnotetext{
$\dagger^{\dagger}$ Telephone cessation counseling is available free to callers to state quitlines (including Medicaid enrollees) in all 50 states and the District of Columbia through the national quitline portal 1-800-QUIT-NOW, and therefore is not included in this report. In June 2011, the Centers for Medicare \& Medicaid Services (CMS) announced that it would offer a 50\% federal administrative match to state Medicaid programs for the cost of state quitline counseling provided to Medicaid enrollees. Although not discussed in this report, some state Medicaid programs cover or otherwise provide access to telephone counseling for at least some Medicaid enrollees.
}

\section{Summary \\ What is already known about this topic?}

Medicaid enrollees smoke cigarettes at a higher rate than do privately insured U.S. residents. States that expand Medicaid eligibility are able to extend coverage to large numbers of adult smokers who are not eligible for traditional Medicaid cessation coverage, thereby substantially increasing the potential impact of Medicaid cessation coverage.

What is added by this report?

By expanding Medicaid eligibility under the Affordable Care Act, 32 states have extended Medicaid cessation coverage to about 2.3 million adult smokers who were not previously eligible for Medicaid. All 32 of these states covered some cessation treatments for all Medicaid expansion enrollees. Nine states covered all nine cessation treatments considered in this study for all Medicaid expansion enrollees, and 19 states covered all seven FDA-approved cessation medications for all enrollees. All 32 states imposed one or more barriers to accessing at least one cessation treatment for at least some enrollees.

What are the implications for public health practices?

States that have expanded Medicaid can take further steps to help smokers quit by covering proven cessation treatments more fully, removing barriers to accessing covered treatments, making Medicaid enrollees and their health care providers aware of these treatments, and monitoring use of these treatments.

\section{Discussion}

Under the Medicaid expansion provision of ACA, states can expand Medicaid eligibility to include adults aged $<65$ years with incomes $\leq 138 \%$ of the Federal Poverty Level. $\$ \$$, 99 As of July 1, 2016, 32 states have expanded Medicaid eligibility, a step which has made Medicaid cessation coverage available to approximately 2.3 million adult smokers who were not previously eligible for Medicaid. Moreover, all of these states covered some cessation treatments for all Medicaid expansion enrollees, and 19 states covered all seven FDA-approved cessation medications for all enrollees. However, only nine states covered all nine cessation treatments, and all 32 states imposed one or more barriers to accessing cessation treatments for at least some enrollees. Several states, including Michigan and Minnesota, have made notable progress in removing barriers to cessation coverage for both their expansion and traditional (i.e., nonexpansion) Medicaid populations in recent years. Other states have made more recent progress in this regard. For example, Maryland removed copayments for cessation

\footnotetext{
$\$ \$$ http://housedocs.house.gov/energycommerce/ppacacon.pdf.

99 Although a June 2012 Supreme Court ruling held that a state cannot lose federal funding for its existing Medicaid program if it does not participate in the expansion, financial incentives exist for all states to expand eligibility for Medicaid coverage (National Federation of Independent Business, et al.v. Kathleen Sebelius, Secretary of Health and Human Services, et al.; 132 S. Ct. 2566 [2012]).
} 
TABLE 1. Estimated number of current smokers aged 18-64 years in Medicaid Expansion-32 states,* December 2015

\begin{tabular}{|c|c|c|c|c|c|c|}
\hline \multirow[b]{2}{*}{ State } & \multicolumn{3}{|c|}{ Adults enrolled in Medicaid } & \multirow[b]{2}{*}{$\begin{array}{c}\text { Medicaid } \\
\text { smoking } \\
\text { prevalence }\end{array}$} & \multicolumn{2}{|c|}{ Adult smokers in Medicaid expansion } \\
\hline & Total no. $^{\dagger}$ & $\begin{array}{l}\text { No. in Medicaid } \\
\text { expansion }^{\dagger}\end{array}$ & $\begin{array}{l}\text { No. newly eligible } \\
\text { in Medicaid } \\
\text { expansion }{ }^{\dagger, \S}\end{array}$ & & Total no.** & $\begin{array}{l}\text { No. newly } \\
\text { eligible** }\end{array}$ \\
\hline Alaska & 124,883 & 8,500 & 8,500 & 30.2 & 2,567 & 2,567 \\
\hline Arizona & $1,873,397$ & 412,957 & 105,711 & 30.4 & 125,622 & 32,157 \\
\hline Arkansas & 919,768 & 291,602 & 266,741 & NA & NA & NA \\
\hline California & NA & NA & NA & NA & NA & NA \\
\hline Colorado & NA & NA & NA & 27.4 & NA & NA \\
\hline Connecticut & 840,619 & 200,988 & 186,967 & 37.0 & 74,426 & 69,234 \\
\hline Delaware & 210,636 & 60,006 & 9,280 & 37.4 & 22,460 & 3,474 \\
\hline District of Columbia & 243,612 & 61,946 & 61,946 & 40.7 & 25,224 & 25,224 \\
\hline Hawaii & 313,126 & 107,485 & 33,427 & NA & NA & NA \\
\hline Illinois & $2,869,749$ & 641,439 & 616,265 & 35.8 & 229,892 & 220,869 \\
\hline Indiana & $1,244,321$ & 361,687 & 222,364 & 48.3 & 174,550 & 107,313 \\
\hline lowa & 585,978 & 146,310 & 135,963 & 43.4 & 63,499 & 59,008 \\
\hline Kentucky & $1,274,166$ & 439,044 & 439,044 & 50.1 & 219,785 & 219,785 \\
\hline Louisiana & $1,444,601$ & NA & NA & 35.9 & NA & NA \\
\hline Maryland & $1,061,749$ & 231,484 & 231,484 & 30.3 & 70,140 & 70,140 \\
\hline Massachusetts & $1,805,041$ & 384,390 & 0 & 32.8 & 126,157 & 0 \\
\hline Michigan & $2,287,620$ & 613,761 & 579,378 & 40.9 & 250,844 & 236,792 \\
\hline Minnesota & $1,186,498$ & 208,492 & 207,683 & 32.6 & 68,031 & 67,767 \\
\hline Montana & 138,970 & NA & NA & 51.3 & NA & NA \\
\hline Nevada & NA & NA & NA & 35.6 & NA & NA \\
\hline New Hampshire & 187,999 & 49,040 & 48,759 & 48.8 & 23,946 & 23,809 \\
\hline New Jersey & NA & NA & NA & 23.0 & NA & NA \\
\hline New Mexico & 840,108 & 235,425 & 235,425 & 30.4 & 71,522 & 71,522 \\
\hline New York & $5,768,918$ & $2,276,859$ & 285,564 & 27.2 & 618,395 & 77,559 \\
\hline North Dakota & NA & NA & NA & 43.8 & NA & NA \\
\hline Ohio & $2,930,308$ & 653,434 & 607,139 & 47.4 & 309,466 & 287,541 \\
\hline Oregon & $1,055,080$ & 518,904 & 452,269 & 35.8 & 185,768 & 161,912 \\
\hline Pennsylvania & $2,670,350$ & 603,335 & 547,962 & 53.2 & 320,793 & 291,351 \\
\hline Rhode Island & 279,851 & 59,280 & 59,280 & 29.8 & 17,671 & 17,671 \\
\hline Vermont & 207,146 & 60,678 & 0 & 36.8 & 22,323 & 0 \\
\hline Washington & $1,813,800$ & 592,114 & 577,422 & 34.2 & 202,562 & 197,536 \\
\hline West Virginia & 554,210 & 174,999 & 174,999 & 48.9 & 85,627 & 85,627 \\
\hline Total & $34,732,504$ & $9,394,159$ & $6,093,572$ & NR & $3,311,270$ & $2,328,858$ \\
\hline
\end{tabular}

Abbreviations: $\mathrm{NA}=$ not available; $\mathrm{NR}=$ not reported.

* Includes the District of Columbia.

† Enrollment estimates were drawn from the Centers for Medicare and Medicaid Services Medicaid Budget and Expenditure System (MBES) CMS 64 Total Medicaid Enrollees - VIII Group Break Out Report, October-December 2015, Updated June 2016 (https://www.medicaid.gov/medicaid/program-information/downloads/ cms-64-enrollment-report-oct-dec-2015.pdf). MBES was missing information for seven expansion states for the period in question.

$\S$ The total VIII group category includes persons who enrolled in Medicaid because of actions in some states that expanded Medicaid eligibility before enactment of the Patient Protection and Affordable Care Act (ACA) and persons who enrolled in Medicaid because of state Medicaid expansions under ACA. The total VIII group newly eligible category only includes the latter group.

" Data were obtained from the Behavioral Risk Factor Surveillance System (BRFSS) 2014 health care access module (http://www.cdc.gov/brfss/). Smoking prevalence estimates were calculated for 2014 BRFSS respondents aged 18-64 years who reported: 1) smoking $\geq 100$ cigarettes during their lifetimes and smoking every day or some days at the time of the interview, and 2) having Medicaid or another state program as the primary source of their health care coverage. The relevant BRFSS question did not distinguish between traditional and expansion Medicaid coverage.

** BRFSS smoking prevalence estimates from 2014 were applied to December 2015 enrollment data to generate estimates of smokers with expansion Medicaid coverage. Although one decimal point prevalence estimates are reported here, two decimal point prevalence estimates were used in calculating the total and newly eligible numbers of smokers in the VIII group.

medications for enrollees in both expansion and traditional Medicaid, effective October 21, 2016. In September 2016, California enacted legislation requiring the state Medicaid program to cover a comprehensive cessation benefit for both the expansion and traditional Medicaid populations, effective January 1, 2017. Providing and promoting evidence-based cessation coverage has been found to be a cost-effective way to help smokers quit. Among the Medicaid population in
Massachusetts, an evidence-based, heavily promoted Medicaid cessation benefit was associated with a reduction in smoking prevalence, from $38.3 \%$ to $28.3 \%$ over a 3 -year period ( 7 ). For each dollar spent on the benefit over a 3-year period, an estimated $\$ 3.12$ in medical savings occurred from averted cardiovascular hospitalizations alone (4).

With regard to tobacco cessation coverage, Medicaid expansion coverage is subject to different ACA provisions than 


\begin{tabular}{|c|c|c|c|c|c|c|c|c|c|}
\hline \multirow[b]{2}{*}{ State } & \multicolumn{9}{|c|}{ Treatment } \\
\hline & $\begin{array}{l}\text { Individual } \\
\text { counseling }\end{array}$ & $\begin{array}{c}\text { Group } \\
\text { counseling }\end{array}$ & $\begin{array}{l}\text { Nicotine } \\
\text { patch }\end{array}$ & $\begin{array}{l}\text { Nicotine } \\
\text { gum }\end{array}$ & $\begin{array}{l}\text { Nicotine } \\
\text { lozenge }\end{array}$ & $\begin{array}{c}\text { Nicotine } \\
\text { nasal spray }\end{array}$ & $\begin{array}{l}\text { Nicotine } \\
\text { inhaler }\end{array}$ & Bupropion & Varenicline \\
\hline Alaska & Yes & No & Yes & Yes & Yes & Yes & Yes & Yes & Yes \\
\hline Arizona & No & No & Yes & Yes & Yes & Yes & Yes & Yes & Yes \\
\hline Arkansas & V & No & V & V & V & $\mathrm{V}$ & V & Yes & Yes \\
\hline California & V & $\mathrm{V}$ & Yes & Yes & Yes & V & V & Yes & Yes \\
\hline Colorado & Yes & Yes & Yes & Yes & Yes & Yes & Yes & Yes & Yes \\
\hline Connecticut & Yes & Yes & Yes & Yes & Yes & Yes & Yes & Yes & Yes \\
\hline Delaware & Yes & No & Yes & Yes & Yes & Yes & Yes & Yes & Yes \\
\hline District of Columbia & NA & NA & Yes & Yes & Yes & V & V & Yes & Yes \\
\hline Hawaii & Yes & V & Yes & Yes & V & V & V & Yes & Yes \\
\hline Illinois & No & No & Yes & Yes & Yes & Yes & Yes & Yes & Yes \\
\hline Indiana & Yes & Yes & Yes & Yes & Yes & Yes & Yes & Yes & Yes \\
\hline lowa & V & V & Yes & Yes & Yes & Yes & Yes & Yes & Yes \\
\hline Kentucky & V & V & Yes & Yes & Yes & Yes & Yes & Yes & Yes \\
\hline Louisiana & No & V & V & V & V & Yes & Yes & Yes & Yes \\
\hline Maryland & Yes & No & Yes & Yes & Yes & Yes & Yes & Yes & Yes \\
\hline Massachusetts & Yes & Yes & Yes & Yes & Yes & Yes & Yes & Yes & Yes \\
\hline Michigan & V & V & Yes & Yes & Yes & Yes & Yes & Yes & Yes \\
\hline Minnesota & Yes & Yes & Yes & Yes & Yes & Yes & Yes & Yes & Yes \\
\hline Montana & Yes & No & Yes & Yes & Yes & Yes & Yes & Yes & Yes \\
\hline Nevada & No & V & V & V & V & Yes & Yes & Yes & Yes \\
\hline New Hampshire & $\mathrm{V}$ & No & V & V & V & Yes & Yes & Yes & Yes \\
\hline New Jersey & V & V & Yes & V & Yes & V & V & Yes & Yes \\
\hline New Mexico & V & V & Yes & Yes & Yes & V & V & Yes & Yes \\
\hline New York & Yes & Yes & Yes & Yes & V & V & V & Yes & V \\
\hline North Dakota & Yes & Yes & Yes & Yes & Yes & Yes & Yes & Yes & Yes \\
\hline Ohio & Yes & Yes & Yes & Yes & Yes & Yes & Yes & Yes & Yes \\
\hline Oregon & V & V & Yes & Yes & V & V & V & Yes & Yes \\
\hline Pennsylvania & Yes & Yes & Yes & Yes & Yes & Yes & Yes & Yes & Yes \\
\hline Rhode Island & Yes & Yes & Yes & Yes & Yes & V & V & Yes & Yes \\
\hline Vermont & Yes & Yes & Yes & Yes & Yes & Yes & Yes & Yes & Yes \\
\hline Washington & Yes & No & Yes & Yes & Yes & Yes & Yes & Yes & Yes \\
\hline West Virginia & No & No & Yes & Yes & V & V & V & Yes & V \\
\hline \multicolumn{10}{|l|}{ Totals } \\
\hline Yes & 17 & 11 & 28 & 27 & 24 & 22 & 22 & 32 & 30 \\
\hline No & 5 & 10 & 0 & 0 & 0 & 0 & 0 & 0 & 0 \\
\hline V & 9 & 10 & 4 & 5 & 8 & 10 & 10 & 0 & 2 \\
\hline NA & 1 & 1 & 0 & 0 & 0 & 0 & 0 & 0 & 0 \\
\hline
\end{tabular}

Abbreviations: $\mathrm{NA}=$ not available; $\mathrm{V}=$ varies by plan.

* Includes the District of Columbia.

traditional Medicaid coverage (5). Unlike traditional Medicaid coverage, Medicaid expansion coverage is subject to Section 1001 of ACA, which requires coverage without cost-sharing of preventive services receiving an A or B rating from the U.S. Preventive Services Task Force (USPSTF) (5). Tobacco cessation intervention has received an A-grade from USPSTF.***, $+\dagger \dagger$

\footnotetext{
*** https://www.uspreventiveservicestaskforce.org/Page/Document/ UpdateSummaryFinal/tobacco-use-in-adults-and-pregnant-women-counselingand-interventions 1 .

计 The federal prohibition on cost-sharing for tobacco cessation services for the Medicaid expansion population in the new eligibility group for adults was explained in CMS guidance issued to state Medicaid agencies in 2012 (https://www.medicaid.gov/Federal-Policy-Guidance/downloads/SMD-12003.pdf). CMS also issued an Information Bulletin in January 2016 on changes in Essential Health Benefit standards affecting Medicaid Alternative Benefit Plans, which reiterates the cost-sharing prohibition (https://www. medicaid.gov/federal-policy-guidance/downloads/cib-01-28-16.pdf).
}

Guidance issued by the departments of Health and Human Services, Labor, and Treasury in May 2014 defines how this provision applies to cessation coverage. ${ }^{\$ \Phi \$}$ To assist with compliance with Section 1001, CMS is contacting states to ensure that they understand the previous guidance and to provide technical assistance for states to achieve compliance. Several states that currently require copayments for some cessation treatments for Medicaid expansion enrollees have indicated that they are planning to remove this requirement.

More comprehensive state Medicaid coverage of cessation treatments is associated with increased use of cessation medications and increased quit rates among smokers enrolled in Medicaid $(6,8)$. Moreover, removing barriers such as

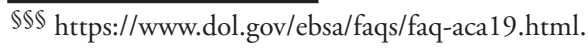


TABLE 3. Barriers to Medicaid expansion coverage of tobacco cessation treatments -32 states, ${ }^{*}$ July $1,2016^{\dagger}$

\begin{tabular}{|c|c|c|c|c|c|c|c|}
\hline State & $\begin{array}{l}\text { Copayments } \\
\text { required }\end{array}$ & $\begin{array}{l}\text { Prior authorization } \\
\text { required }\end{array}$ & $\begin{array}{l}\text { Counseling } \\
\text { required for } \\
\text { medications }\end{array}$ & $\begin{array}{l}\text { Stepped-care } \\
\text { therapy }^{\S}\end{array}$ & $\begin{array}{l}\text { Limits on } \\
\text { duration }\end{array}$ & $\begin{array}{l}\text { Annual limits on } \\
\text { quit attempts }\end{array}$ & $\begin{array}{l}\text { Lifetime limits on } \\
\text { quit attempts }\end{array}$ \\
\hline Alaska & Yes & Yes & No & No & Yes & Yes & No \\
\hline Arizona & No & No & No & No & Yes & Yes & No \\
\hline Arkansas & V & V & No & No & V & V & No \\
\hline California & No & V & No & V & V & V & No \\
\hline Colorado & V & V & V & No & Yes & Yes & No \\
\hline Connecticut & No & Yes & No & No & No & Yes & No \\
\hline Delaware & Yes & Yes & Yes & Yes & Yes & Yes & No \\
\hline District of Columbia & No & V & No & No & V & V & No \\
\hline Hawaii & No & V & V & V & V & Yes & No \\
\hline Illinois & Yes & No & No & No & No & No & No \\
\hline Indiana & No & Yes & V & V & Yes & Yes & No \\
\hline lowa & No & Yes & Yes & Yes & Yes & Yes & No \\
\hline Kentucky & No & Yes & No & V & Yes & Yes & No \\
\hline Louisiana & V & $\mathrm{V}$ & V & V & V & $\mathrm{V}$ & No \\
\hline Maryland & NA & Yes & No & Yes & No & Yes & No \\
\hline Massachusetts & Yes & Yes & No & No & No & Yes & No \\
\hline Michigan & No & No & No & No & V & No & No \\
\hline Minnesota & No & NA & No & No & V & No & No \\
\hline Montana & No & Yes & No & NA & NA & NA & No \\
\hline Nevada & No & Yes & No & V & Yes & Yes & No \\
\hline New Hampshire & V & No & No & No & V & $\mathrm{V}$ & No \\
\hline New Jersey & No & V & No & V & No & V & V \\
\hline New Mexico & No & V & V & No & V & V & No \\
\hline New York & Yes & V & No & V & Yes & Yes & No \\
\hline North Dakota & No & No & No & No & Yes & Yes & No \\
\hline Ohio & V & V & No & V & V & V & No \\
\hline Oregon & No & V & V & V & V & V & No \\
\hline Pennsylvania & V & V & No & No & Yes & Yes & No \\
\hline Rhode Island & No & Yes & V & V & Yes & Yes & No \\
\hline Vermont & Yes & Yes & No & Yes & Yes & Yes & No \\
\hline Washington & No & V & V & V & Yes & Yes & No \\
\hline West Virginia & V & V & V & No & V & V & No \\
\hline \multicolumn{8}{|l|}{ Totals } \\
\hline Yes & 6 & 12 & 2 & 4 & 14 & 18 & 0 \\
\hline No & 18 & 5 & 21 & 15 & 5 & 3 & 31 \\
\hline V & 7 & 14 & 9 & 12 & 12 & 10 & 1 \\
\hline NA & 1 & 1 & 0 & 1 & 1 & 1 & 0 \\
\hline
\end{tabular}

Abbreviations: $N A=$ not available; $V=$ varies by plan.

* Includes the District of Columbia.

† Barriers apply to one or more cessation treatments.

$\S$ Refers to a requirement that a person try and fail to quit with one cessation medication before being able to access another cessation medication.

copayments, which pose a financial obstacle, and prior authorization, which can delay accessing services unless a process is in place to expedite authorization, further increases access to these treatments $(3,5)$. Communicating to smokers and health care providers that cessation treatments are covered is also important to ensure that they are aware of and use covered treatments $(5,7)$. A recent study found that only approximately $10 \%$ of Medicaid enrollees who smoked received a prescription for a tobacco cessation medication in 2013, with wide variation in use of cessation medications across states (10). Medicaid cessation coverage has the greatest effect when it is available to large numbers of smokers and is widely used $(5,7)$.

The findings in this report are subject to at least four limitations. First, enrollment estimates were drawn from a new CMS reporting system whose primary purpose is to allow states to claim the enhanced Medicaid expansion federal matching rate; this system was missing information for seven expansion states for the assessment period. Second, the state smoking prevalence estimates were based on respondents who reported that they smoked and were enrolled in Medicaid; these estimates were not available for three states, and the relevant BRFSS question did not distinguish between traditional and Medicaid expansion coverage. In addition, 2014 smoking prevalence estimates were applied to December 2015 enrollment data to generate estimates of smokers enrolled in Medicaid expansion. Third, in cases where official coverage documents were not publicly available, were outdated, or conflicted with one another, state government personnel were consulted to provide additional 
documentation or resolve discrepancies; this information might be inaccurate in some cases. Finally, cessation coverage can vary widely across Medicaid expansion managed care plans, making it challenging to determine coverage.

The 32 states that have expanded Medicaid eligibility under ACA are providing Medicaid cessation coverage to approximately 2.3 million adult smokers who were not previously eligible for Medicaid. These states can take further steps toward helping these smokers quit by more fully covering cessation treatments, removing barriers to accessing covered treatments, making Medicaid enrollees and providers aware of these treatments, and monitoring use of these treatments (3,5-7). State Medicaid programs that take these actions can substantially reduce tobacco use and tobacco-related disease and health care costs among a vulnerable population (4-7). Opportunities exist for the 19 states that have not expanded Medicaid eligibility to reduce smoking among low-income adults by making their cessation coverage more broadly available. Providing barrierfree access to cessation treatments and promoting their use are important components of a comprehensive approach to reducing tobacco use $(3,5-7)$.

\section{Acknowledgments}

Stephanie Bell, Sarah Delone, Kirsten Jensen, Deirdra Stockmann, Centers for Medicare \& Medicaid Services; Paul G. Billings, Susan J. Rappaport, Kim Lacina, Erika Sward, Katherine Pruitt, Bill Blatt, Thomas Carr, Allison MacMunn, Gregg Tubbs, Ara Janoyan, Catherine Fields Chandler, Tenásha Williams, nationwide staff members, American Lung Association; Allison MacNeil, Lei Zhang, Office on Smoking and Health, National Center for Chronic Disease Prevention and Health Promotion, CDC.

${ }^{1}$ American Lung Association, Chicago, Illinois; ${ }^{2}$ Office on Smoking and Health, National Center for Chronic Disease Prevention and Health Promotion, CDC. Corresponding author: Stephen Babb, sbabb@cdc.gov, 770-488-1172.

\section{References}

1. Jamal A, King BA, Neff LJ, Whitmill J, Babb SD, Graffunder CM. Current cigarette smoking among adults-United States, 2005-2015. MMWR Morb Mortal Wkly Rep 2016;65:1205-11. http://dx.doi. org/10.15585/mmwr.mm6544a2

2. Xu X, Bishop EE, Kennedy SM, Simpson SA, Pechacek TF. Annual healthcare spending attributable to cigarette smoking: an update. Am J Prev Med 2015;48:326-33. http://dx.doi.org/10.1016/j. amepre.2014.10.012

3. US Public Health Service. Treating tobacco use and dependence: 2008 update_-clinical practice guideline. Rockville, MD: US Department of Health and Human Services, US Public Health Service; 2008. https:// www.ncbi.nlm.nih.gov/books/NBK63952/

4. Richard P, West K, Ku L. The return on investment of a Medicaid tobacco cessation program in Massachusetts. PLoS One 2012;7:e29665. http:// dx.doi.org/10.1371/journal.pone.0029665

5. McAfee T, Babb S, McNabb S, Fiore MC. Helping smokers quitopportunities created by the Affordable Care Act. N Engl J Med 2015;372:5-7. http://dx.doi.org/10.1056/NEJMp1411437

6. Greene J, Sacks RM, McMenamin SB. The impact of tobacco dependence treatment coverage and copayments in Medicaid. Am J Prev Med 2014;46:331-6. http://dx.doi.org/10.1016/j.amepre.2013.11.019

7. Land T, Warner D, Paskowsky M, et al. Medicaid coverage for tobacco dependence treatments in Massachusetts and associated decreases in smoking prevalence. PLoS One 2010;5:e9770. http://dx.doi. org/10.1371/journal.pone.0009770

8. Ku L, Brantley E, Bysshe T, Steinmetz E, Bruen BK. How Medicaid and other public policies affect use of tobacco cessation therapy, United States, 2010-2014. Prev Chronic Dis 2016;13:E150. http://dx.doi. org/10.5888/pcd13.160234

9. Singleterry J, Jump Z, DiGiulio A, et al. State Medicaid coverage for tobacco cessation treatments and barriers to coverage-United States, 2014-2015. MMWR Morb Mortal Wkly Rep 2015;64:1194-9. http:// dx.doi.org/10.15585/mmwr.mm6442a3

10. Ku L, Bruen BK, Steinmetz E, Bysshe T. Medicaid tobacco cessation: big gaps remain in efforts to get smokers to quit. Health Aff (Millwood) 2016;35:62-70. http://dx.doi.org/10.1377/hlthaff.2015.0756 